\title{
Environmental Geotechnics in Practice
}


Downloaded by [] on [25/04/23]. Copyright $\odot$ ICE Publishing, all rights reserved. 


\section{Environmental Geotechnics in Practice}

Introduction and case studies

Robert W Sarsby CEng FICE 
Published by ICE Publishing, One Great George Street, Westminster, London SW1P 3AA.

Full details of ICE Publishing representatives and distributors can be found at: www.icebookshop.com/bookshop_contact.asp

\section{Other titles by ICE Publishing:}

Environmental Geotechnics, Second edition

Robert W Sarsby. ISBN 978-0-7277-4187-5

Contaminated Land Guidance, Third edition

Jo Strange, Nick Langdon and Alex Large. ISBN 978-0-7277-6106-4

Infrastructure in a Circular Economy

David WJ Greenfield. ISBN 978-0-7277-6319-8

www.icebookshop.com

A catalogue record for this book is available from the British Library

ISBN 978-0-7277-6363-1

(c) Thomas Telford Limited 2019

ICE Publishing is a division of Thomas Telford Ltd, a wholly owned subsidiary of the Institution of Civil Engineers (ICE).

All rights, including translation, reserved. Except as permitted by the Copyright, Designs and Patents Act 1988, no part of this publication may be reproduced, stored in a retrieval system or transmitted in any form or by any means, electronic, mechanical, photocopying or otherwise, without the prior written permission of the Publisher, ICE Publishing, One Great George Street, Westminster, London SW1P 3AA.

This book is published on the understanding that the author is solely responsible for the statements made and opinions expressed in it and that its publication does not necessarily imply that such statements and/or opinions are or reflect the views or opinions of the publishers. While every effort has been made to ensure that the statements made and the opinions expressed in this publication provide a safe and accurate guide, no liability or responsibility can be accepted in this respect by the author or publishers.

While every reasonable effort has been undertaken by the author and the publisher to acknowledge copyright on material reproduced, if there has been an oversight please contact the publisher and we will endeavour to correct this upon a reprint.

Cover photo: France Pas de Calais Loos en Gohelle the twin slag heaps of pit head 11/19 mine site listed as World Heritage by UNESCO. Hemis/Alamy Stock Photo.

Commissioning Editor: Michael Fenton

Development Editor: Audra Taylor

Production Editor: Madhubanti Bhattacharyya

Marketing Specialist: April Asta Brodie

Typeset by The Manila Typesetting Company

Index created by Pierke Bosschieter

Printed and bound in Great Britain by TJ International, Padstow 


\section{Contents}

Preface

01

\section{Introduction}

1.1. Background

1.2. Waste disposal by landfill

1.3. Contaminated and damaged land

1.4. Waste dumps - tips, tailings and lagoons

1.5. Environmental geotechnics Sources

\section{Engineered waste disposal by landfill}

02

19

2.1. Landfill liners 19

2.2. Landfill caps 22

2.3. Fluid management 22

2.4. Case histories 23

Sources 66

$03 \ldots \ldots \ldots \ldots \ldots \ldots \ldots$ Contaminated and damaged land $\quad 69$

3.1. Contaminated land treatment 69

3.2. Damaged land treatment 71

3.3. Case histories 76

Sources $\quad 118$

$04 \ldots \ldots \ldots \ldots \ldots \ldots \ldots \ldots \ldots$ Waste dumps - tips, tailings and lagoons 121

4.1. Tips 121

4.2. Tailings dams 121

4.3. Lagoons and ponds 123

4.4. Case histories 125

Sources 160

$05 \ldots \ldots \ldots \ldots \ldots \ldots \ldots$ Concluding remarks $\quad 163$

5.1. General 163

5.2. Environmental geotechnics 163

5.3. Points for the future 166

$\begin{array}{ll}\text { Index } & 169\end{array}$ 
Downloaded by [] on [25/04/23]. Copyright $\odot$ ICE Publishing, all rights reserved. 


\section{Preface}

For centuries, mankind has been dumping all manner of materials (both toxic and non-toxic) on land, usually in an uncontrolled manner. However, over the past 100 years the world has changed dramatically in terms of the size of its population, the amount of waste produced and dumped globally, rapid urbanisation, and the desirability or necessity of reusing land that has been affected adversely by former industrial usage. In response to these pressures, there have been developments in the technical aspects of geotechnical engineering to address environmental concerns and problems, as illustrated in the case studies contained within this book. This is the realm of environmental geotechnics, wherein construction involves significant actual, or potential, interaction between ground engineering and the environment.

The overall scope of the book is the past performance of landfills, land remediation works and waste tips and the effect of potential future scenarios. The case histories relate to sites in several different countries in Europe, America and Asia. These cases show mistakes that have occurred, successes that have been achieved, and how there has been a range of innovations in order to deal with a wide variety of problem sites in a safe and effective manner. It is believed that examination of the cases histories and awareness of the associated lessons can help current designers and constructers involved in environmental geotechnics to address problems that will be posed in the future and avoid system failures and environmental disasters. Specifically, the aims of this book include the following.

- Identify lessons to be learnt from past 'geoenvironmental' works to prevent mistakes that are foreseeable and avoidable in the future.

- Emphasise that any waste disposal facility, whether it be for municipal refuse, commercial waste or mineral spoil, should be properly engineered if negative impacts on the environment and society are to be avoided.

- Identify the key elements of a variety of geoenvironmental systems and explain each element's role in protecting the environment.

- Demonstrate that it is possible to use geotechnical principles and practices to design suitable ways of disposing of waste and rehabilitating land damaged by waste dumping within a framework of a generic 'source-pathway-target' mechanism.

- Encourage readers not to apply a regimented formulaic approach to geoenvironmental practice and to critically appraise or assess the applicability of any design concept and data for the whole lifetime of a particular site, that is, during its construction, operational, closure and post-closure phases.

The initial part of the book contains a background to environmental geotechnics. The case histories have been chosen to cover technical issues associated with particular aspects of environmental geotechnics. Over half of the histories concern some form of 'failure' that promoted significant changes in geoenvironmental practice. The case histories are presented in chronological order because individual sites became larger and more complex with time and this caused more and more problems to arise. However, in general there was no true continuous 'technological development' of these facilities, that is, one cannot say that one change or development in disposal practice led to 
another change or development, and so on. The case histories contain appropriate technical detail to explain what has happened in a qualitative way, without assuming an in-depth knowledge of geotechnical engineering or soil mechanics. The influence of ambient and atmospheric conditions on the stability of man-made areas of waste dumping is particularly important and key points from the case histories include the following.

- Water has a major influence on the performance and stability of waste masses (in a variety of ways).

- Environmental conditions are very important because waste masses exist in the open air with little, if any, protection from the elements.

- Climate change effects will invalidate some of the design concepts and parameter values that were diligently applied over the past decades and hence cause unforeseen mechanisms, site behaviour and occurrences of failure.

- The stability of existing tips or heaps of waste material should always be regarded as questionable because of a lack of engineering design and construction coupled with the potential for waste material alteration over time.

Global climate change is now causing increased frequency and severity of extreme weather events, elevated ambient temperatures and rising sea levels. And these changes pose the threat that current and past geotechnical works designed to protect the environment will be compromised and destabilised so that pollution migration is promoted and severe environmental contamination and public health threats will ensue. Hence, the overarching consideration in the writing of this book has been to provide a readable and informative text for people learning about, or actively involved in, environmental geotechnics. The book is intended to serve the needs of undergraduate and postgraduate students taking a wide variety of courses, for example, Civil Engineering, Civil and Environmental Engineering, Environmental Engineering, Environmental Science, Engineering Geology or Waste Management. The book is also intended to be of benefit to persons working in industries where there is significant interaction with the ground (construction, waste disposal, mining and quarrying, etc.) who wish to refresh or augment their knowledge. 
Acknowledgements I would like to acknowledge the kind help and assistance of the following people and organisations:

Canadian Geotechnical Society; University of Chile, Santiago; County Sanitation Districts of Los Angeles County, USA; Delft University, the Netherlands; Department of Enterprise, Trade and Investment, Northern Ireland; Kev Duncan; Durham Mining Museum; Dr M Fenton; Learning Resource Hub staff (particular thanks to Claire) at the Institution of Civil Engineers, London; Dr I Kajewski; Steve Kay; Ministry of Science and Higher Education, Poland; National Records of Scotland; Sam Pedroza; Kieran Parker; Mark Richardson; Robertson Library at Curtin University, Western Australia; Irene Sarsby (to whom I am especially grateful); West Lothian County Council; Wrocław University, Poland. 
Downloaded by [] on [25/04/23]. Copyright $\odot$ ICE Publishing, all rights reserved. 


\section{About the author}

Dr Robert (Bob) Sarsby CEng FICE has spent more than 40 years working in geotechnical engineering. Much of his work has had significant environmental interaction or content. During his time as a Professor at Anglia Ruskin, Bolton and Wolverhampton Universities, he promoted the inclusion of environmental geotechnics within construction education. He has published numerous technical articles and two editions of Environmental Geotechnics, as well as organising five international conferences concerning geotechnics and the environment (the GREEN series). He is a Fellow of the Institution of Civil Engineers and has received the Manby Premium (from the Institution of Civil Engineers) for his work on construction noise. 
Downloaded by [] on [25/04/23]. Copyright $\odot$ ICE Publishing, all rights reserved. 


\section{Glossary}

Adit

Anaerobe

Angle of draw

Aquiclude

Attenuation

Autochthonous

Backsapping

Bentonite

Benzene

Bing

Biodegradation

Bioremediation

BOD

Boulder clay

BTEX

Carbon tetrachloride

\section{Carcinogen}

Porous, highly adsorptive, form of carbon used to remove impurities from liquids and gases Horizontal or slightly inclined passage dug specifically to access underground workings Organism that can grow in the absence of oxygen or air Angle (measured from the vertical) defining the extent of propagation of subsidence (at ground level) from an underground void

Impermeable, or very lowpermeability, stratum or body that acts as a barrier to the flow of water Reduction in contaminant concentration, availability or toxicity through biological, chemical or physical processes Indigenous to a particular location Retrogressive removal of solid material from the face of a slope commonly, erosion at the toe of a slope due to seepage and uncontrolled water egress Clay that swells greatly as it absorbs water, and can be used to form a thincotropic mud Highly flammable aromatic hydrocarbon used as a solvent and in the synthesis of numerous chemicals; a known carcinogen Scottish term for a spoil heap or tip Decomposition of a compound into smaller chemical subunits through the action of organisms, typically microorganisms, such as bacteria and fungi

Elimination, attenuation or transformation of contaminating substances through the use of biological processes Biological oxygen demand: a measure of the biodegradable organic pollution present in a watercourse that will remove oxygen from the water as it is decomposed Equivalent to 'till' Benzene, toluene, ethylbenzene and xylene

Volatile non-flammable liquid used as a solvent or cleaning fluid Substance that produces cancer 
Chlorinated hydrocarbon Chemically and thermally stable compound used mainly in the manufacture of synthetic solvents and insecticides

COD Chemical oxygen demand: a measure of the amount of oxidisable pollution in surface water or wastewater

Colluvium

Comminution

CPT

Cretaceous

Crown hole

Cytogenetics

Day level

Defra

Dioxin

Dip

DNAPL

Drained condition

Drain tile

Effective cohesion
A collection of soil and rock fragments deposited by run off or melt water

Reduction in size of a particle by breaking it into smaller pieces

Cone penetration test

Geological time period with a relatively warm climate and high sea level with numerous inland seas, which were habitats for many marine organisms: the period's name reflects the extensive chalk deposits of this age in Europe Void at the ground surface caused by collapse of the roof of old underground mine workings so that it and the overlying strata fall into the space formed by mining Branch of genetics that correlates the structure of chromosomes with heredity and variation Tunnel driven directly from the surface to gain access to minerals Department for Environment, Food and Rural Affairs (UK)

Any of a number of mostly poisonous chemical by-products of the manufacture of certain herbicides and bactericides The angle that a rock unit, fault or other rock structure, makes with a horizontal plane

Dense non-aqueous phase liquid: a liquid that is both denser than water and immiscible in, or insoluble in, water.

State where there is no pressure in the fluid in the pores between particles; this does not mean that the porous medium is dry American term for a porous drainage pipe (which typically has a circular or square cross-section), such as would be used in a French drain Apparent inherent shear strength of a soil or other particulate medium, designated $c^{\prime}$ : perhaps analogous to the interlock between stones in a dry-stone wall 
Effective friction angle

Effective stress

Environment Agency

Foul lime

Freestone

Gault clay

Geonet

Grouting

Gull

HDPE

Head

Hydrophobic

ICRCL

Inclinometer

Lacustrine deposit

Lambeth group
Indicator of the magnitude of the sliding resistance between particles, designated $\phi^{\prime}$ : usually used in the form $\tan \phi^{\prime}$, which can be thought of as equivalent to a friction coefficient Notional stress, which is an indicator of the magnitude of the contact stress between solid bodies Non-departmental public body with responsibilities relating to the protection and enhancement of the environment in England

Lime that was contaminated primarily by cyanide compounds as a result of being used to purify coal gas

Type of rock whose structure allows it to be sawn or 'squared up' in any direction, unlike most other rocks, which contain distinct layers Stiff, blue clay deposited in a marine environment during the Cretaceous period Stiff net of polymeric material used in the ground The injection of a stabilising or setting medium, via pipes inserted into the ground, into large subterranean voids, channels or fissures within soils and rocks Underground passage or void formed by relative movement of rock masses

High-density polyethylene Deposits consisting of fragmented material (with a possible wide range of particle sizes), which, following weathering, have moved down-slope through a process of solifluction

Tending not to dissolve in, mix with, or be wetted by, water Interdepartmental Committee for Reclamation of Contaminated Land (UK)

Instrument measuring tilt relative to the direction of gravity, which is used to detect lateral movement of ground Layer of sediment formed by deposition of particles when land is covered by water

Group of sediments comprising a mixture of stiff and hard clays, silts, sands and gravel, which vary significantly both laterally and vertically (formerly called the Woolwich and Reading Beds) 
Major aquifer

Minor aquifer

Mutagen

Normally consolidated soil Soil that exists under an effective

Oolitic limestone

Opencast mining

Overconsolidated soil

PAH

PCB

PET

PFA stress state that has not been exceeded in the soil's history

Deposits that have high permeability and high water storage capacity and may support water supply on a strategic scale (now called a principal aquifer) Permeable layer capable of supporting water supplies at a local rather than strategic scale (now called a secondary aquifer) Scale rating earthquake intensity from I (nothing) to X (extreme) using a range of key responses: lower values (I to V) deal with the manner in which people are affected, while higher values (VI to $\mathrm{X}$ ) relate to observed structural damage

Substance or agent that can induce Substance or agent Sedimentary rock composed of spherical grains that have been formed by successive deposition of concentric layers of calcium carbonate Type of surface mining in which the mineral resource is removed using wide holes or pits dug from the ground surface, similar to strip mining but occupies much less land area at any one time; also called open-pit or open-cut mining Soil that exists under an effective stress state that is less than that which the soil has experienced in its history

Polycyclic aromatic hydrocarbon: found in coal and tar deposits; can be formed by either natural or man-made combustion Polychlorinated biphenyl: a very stable compound, once used widely as dielectric in electrical apparatus and coolant fluid for heat transfer Polyethylene terephthalate: the most common thermoplastic polymer resin of the polyester family; used in fibres for clothing, containers for liquids and foods and, in combination with glass fibre, for engineering resins Pulverised fuel ash: produced by coal-burning electricity generating stations 
Phreatic surface

Phytoremediation

Piezometer

Polder

Polysaccharide

Richter scale

Roadway

Room and pillar working

Sparging

Spent oxide

Stoop

Strike

Strip mining
The ground level at which pore water pressure is equal to atmospheric pressure, equivalent to 'water table'

The use of plants or vegetation for in situ removal, degradation or containment of contaminants within polluted soil, sludges or groundwater Device for measuring the pressure in water within the pores of a particulate medium Area of low-lying land reclaimed from the sea or a lake, typically by encircling it with dykes and then pumping water from inside the dykes; it is an artificial hydrological entity that has no overland connections with outside water, its groundwater regime being controlled by man-made means Any one of the class of carbohydrates whose molecules contain linked monosaccharide (a simple sugar) units, e.g. starch, cellulose

Logarithmic scale of earthquake size; a change of unity corresponds to a ten-fold change in earthquake magnitude, an increase of 0.2 indicates an increase in released energy of 32 times

Underground passage in a mine created for access and transport of excavated material

Method of working a coal seam where discrete pillars of coal are left to support the roof; also called 'pillar and stall' or 'stoop and room' Injecting a gas (usually air or steam) under pressure into the groundwater to promote the movement of pollutants Compound used in the purification of coal gas; it contains high concentrations of free sulphur, sulphates and cyanides and is highly acidic Column, or pillar, of rock left in a mine to support the roof The geographical direction of a line created by the intersection of a plane and the horizontal Mining a seam of mineral by first removing a long strip of the overlying soil and rock; most commonly used to mine coal and lignite (brown coal) 
Subsidence

Surfactant

SVE

Swale

Teratogenic

Tetrachloroethylene

Thanet Sand

Thixotropic

Till

Trichlorophenol

Tritium

Undrained conditions

Vadose zone

VOC
Settlement of the ground surface due to the removal of mineral resources within the ground, whether they be solid, liquid or gas

Detergent compound that can reduce the surface tension of a liquid (thereby aiding removal of the liquid from the surface of particles)

Soil vapour extraction

Low tract of land, especially one that is moist or marshy; may be a natural or a man-made feature Producing malformation in a foetus Colourless liquid widely used for dry cleaning of fabrics

Fine-grained sand that, at its base, is interbedded with silts and clays

A material that 'sets' as a gel when it is undisturbed but becomes fluid when it is stirred

Clay soil that has been transported and deposited by, or from, glacier ice with little or no sorting and contains a wide range of particle sizes

Synthetic crystalline compound used as an insecticide and preservative and in the synthesis of pesticides Radioactive isotope of hydrogen with extremely rare natural occurrence; used as a source of luminescence in watches and instruments and as a tracer in metabolic studies

Situation in which there is insufficient time for pore fluid to exit or enter from a particulate medium when stress changes occur; this situation can occur because the stress change is very rapid or the medium has low permeability, or both

Unsaturated zone of soil above the water table

Volatile organic compound, e.g. formaldehyde 